\title{
A material flow-based approach for diagnosing urban ecosystem health
}

\author{
Xiaoqing Shi*, Jianxin Yang \\ State Key Laboratory of Urban and Regional Ecology, Research Center for Eco-Environmental Sciences, Chinese Academy of Sciences, 18 Shuangqing Road,
} P.O. Box 2871, Beijing 100085, PR China

\section{A R T I C L E I N F O}

\section{Article history:}

Received 28 November 2011

Received in revised form

1 August 2013

Accepted 23 September 2013

Available online 22 October 2013

\section{Keywords:}

Urban ecosystem

Health diagnosis

Material flow

\begin{abstract}
A B S T R A C T
Urban ecosystem health is an important concept in sustainable development. Knowledge of health status is crucial to maintaining the health of urban ecosystems. Existing methods for assessing urban ecosystem health often focus on a synthesizing assessment but neglect analysis of process. These approaches often rely on a complex indicator system that includes social, economic and environmental factors and use synthesis indicators. This means that their ability to provide diagnosis information for decision makers is limited. For meeting this need, this paper developed a diagnosis approach based on material flow for assessing urban ecosystem health.

A healthy urban ecosystem should be able to support urban development and have enough resilience to recover from ecological environmental stress. Healthy material flow can support the function of the system. Therefore material flow can be regarded as a key factor that reflects the health of an urban ecosystem. This paper explores the mechanism for material flow between urban and natural ecosystems and reveals the main problems that affect urban ecosystem health. A material flow model of urban ecosystems is established by using this mechanism. By using this model, a diagnosis framework is developed for diagnosis of urban ecosystem health. The framework consists of function analysis, input -output flow analysis, health assessment, and function optimization. It focuses on developing a material flow-based diagnosis approach and an indicator system including function-based indicators and effectbased indicators. Case studies show that this approach can not only diagnose the health problems of an urban ecosystem but can also identify the main causes of the problems. Therefore our approach can aid decision makers in making a timely and informative diagnosis of urban ecosystem health to support planning and management decisions.
\end{abstract}

(c) 2013 Elsevier Ltd. All rights reserved.

\section{Introduction}

Sustainable development is increasingly threatened by environmental problems caused by urban development (WCED, 1987). For the development of cities, natural ecosystems such as land, forests and water are exploited, resulting in changes in the components, structure and function of natural ecosystems (Hruska, 2006). The landscape is fragmented, natural species are reduced and some may become extinct, and exotic organisms and waste are introduced; therefore, material cycles are drastically changed, which can cause serious problems for urban ecosystem health, such as ecosystem degradation and environmental pollution. Many human-dominated ecosystems have become highly stressed and dysfunctional (Rapport et al., 1998b). There is an urgent need for

\footnotetext{
* Corresponding author. Tel./fax: +86 1062849805

E-mail address: shixq@rcees.ac.cn (X. Shi).
}

valid diagnosis and assessment of urban ecosystem health (Guidotti, 1995; Rapport et al., 1999).

Because the concept of urban ecosystem health is a subjective notion and an urban ecosystem is a complex social-economicenvironmental integrated system, it is hard to give a unified definition to guide an assessment. Therefore, there are different health assessment indicators from varied perspectives. The existing methods for assessing urban ecosystem health mainly rely on the following types of indicators shown in Table 1: (1) Indicator systems, which often include social-economic-environmental systems and are established on a systemic view. (2) Ecological indices, which often consist of some specific ecological indicators for a specific research objective in the urban ecosystem. (3) Complex indices, which often integrate some specific indicators to assess urban ecosystem health according to a specific view, and (4) Others, which are more relative indicators to assess urban ecosystem health. 
Table 1

The classification of urban ecosystem health indicators.

\begin{tabular}{|c|c|}
\hline Category & Description \\
\hline Indicator system & $\begin{array}{l}\text { A set of general indicators of ecosystem health that includes vigor, organization and resilience (Costanza, 1992; Rapport, 1998a); } \\
\text { A framework for urban ecosystem health that included individual, household and neighborhood levels (Spiegel et al., 2001); } \\
\text { A biophysical UEH indicator system with } 17 \text { related emergy-based indices integrating vigor-structure-resilience-ecosystem } \\
\text { service-population health (Su et al., 2009a); } \\
\text { An indicator system within the PSR framework including ecological-agricultural-production and living subsystem (Zeng et al., 2005); }\end{array}$ \\
\hline Ecological indices & $\begin{array}{l}\text { Three ecological indices of the ecosystem health for water environment quality (Montefalcone, 2009); } \\
\text { An ecosystem health index methodology (EHIM) for assessing lake ecosystem health (Xu et al., 2005); }\end{array}$ \\
\hline Complex indices & $\begin{array}{l}\text { Eco-efficient and disease indicators (Zhang et al., 2008); } \\
\text { An emergy-based urban ecosystem health index (Liu et al., 2009); } \\
\text { The holistic ecosystem health indicator (HEHI) which integrates data from the ecological, social and interactive dimensions } \\
\text { (Wiegand et al., 2010); }\end{array}$ \\
\hline Others related & $\begin{array}{l}\text { Agro-urban ecosystem health (Waltner-Toews et al., 2005; Landis, 1995); } \\
\text { Nine health determinant indices (Takano and Nakamura, 2001); } \\
\text { The Millennium Ecosystem Assessment (Alcamo and Bennett, 2003); } \\
\text { Household sustainable consumption indicators (Caeiro et al., 2012) }\end{array}$ \\
\hline
\end{tabular}

Generally, urban ecosystem health largely depends on the functions of the urban ecosystem and its surrounding environments. Here, the functions include production, consumption and assimilation. Environments include the natural, social and economic environments. Their links are indirect, as functioning is the internal reflection of the system but the environmental effect is an external reflection of the system. Consequently, indicators of urban ecosystems health may be based either on system function (function-based) or on the environmental effect (effect-based). For example, water quality indicators and air quality indicators are effect-based indicators, while cleaner production indicators and wastes control rate are function-based indicators. Effect-based indicators often can show problems in the system but do not provide reasons for these effects. Function-based indicators are the opposite. Evaluation based on means-based indicators is easy to implement but does not allow an actual evaluation of environmental impact. Effect-based indicators allow for a better evaluation of environmental impact but may be difficult to conduct because they are complicated (Hansen, 1996; Van der Werf and Petit, 2002).

Along with an indicator system, a specific assessment model is usually needed to use the indicator data to express the assessment results of urban ecosystem health (UEHA). The current assessment models of UEHA mainly include some specific mathematical models, e.g., fuzzy synthetic assessment (e.g., Zhou and Wang, 2005); set pair analysis (Su et al., 2009b) and attribute theory (e.g., Wen and Xiong, 2008). They all focus on synthetic analysis.

In summary, the existing assessment methods have led to some progress in the assessment of urban ecosystem health. Most of them have the common characteristic of being convenient for assessing the status of urban ecosystem health by using synthesis indicators. However, these approaches often focus on a synthesis assessment but neglect assessment of process. Thus, these approaches only weakly link effects with causes. They are still primitive in giving a diagnosis signal of management of urban ecosystem health and have a limited ability to identify the causes of health problems of urban ecosystems. To address this deficiency, we investigated an approach for diagnosing urban ecosystem health by analyzing the input and output of material flow. Material flow is the "lifeblood" of cities, and is thus a reflection of urban ecosystem health. Such a diagnosis can let decision makers know not only of health problems of the urban ecosystem but also their causes. This approach will be very helpful for decision makers to make practical feasible strategies to maintain urban ecosystem health (Van der Werf et al., 2009).
We start with an urban ecosystem function analysis and a material flow process analysis between urban and natural ecosystems. We then establish a process assessment model of urban ecosystem health and a diagnosis framework which included function analysis, input-output flow analysis, health assessment, and function optimization. In this framework, we focus on developing a diagnosis indicator system and a material flow-based diagnosis approach for urban ecosystem health. We next give two case studies of its application and analyze the results of the application of the approach.

\section{Material flow analysis}

Material flow analysis (MFA) is a methodology that focuses on tracking and quantifying a substance or group of substances as it moves through a system and is the primary tool used to understand the metabolic processes for anthropological activity (Harper and Graedel, 2004). Except for natural disasters, ecological and environmental problems are often caused by unsuitable metabolic processes such as non-recycled flow of materials. Therefore, material flow analysis can help in identifying and in diagnosing the health of an urban ecosystem. A simple MFA framework is illustrated in Fig. 1 (Brunner and Rechberger, 2004). This paper will present a diagnosis method based on the process analysis of material flow.

\subsection{Urban ecosystem functions and health}

An urban ecosystem consists of several interlinked subsystems, including social, economic, institutional, and ecological systems, each representing a complex system and each affecting

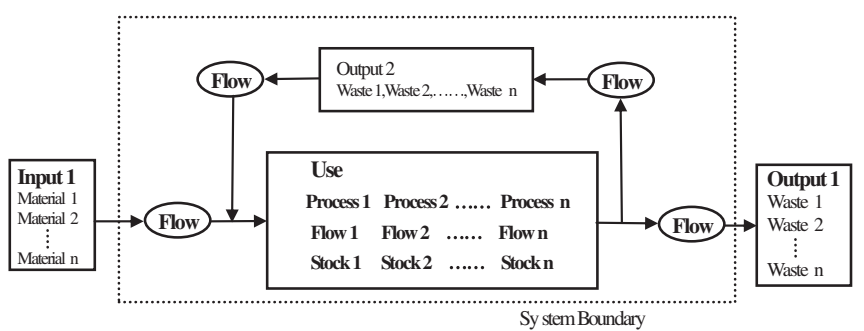

Fig. 1. A simple framework for MFA. MFA provides a tool for analyzing the material metabolism process from input to output. 
Table 2

Urban ecosystem functions.

\begin{tabular}{|c|c|}
\hline Function type & Examples \\
\hline Production & $\begin{array}{l}\text { Resource input: explore resources to support production } \\
\text { such as industry and agriculture, living, transportation, } \\
\text { business, healthcare, education, culture, finance and } \\
\text { services. }\end{array}$ \\
\hline Consumption & Living, entertainment, social activities. \\
\hline Restoration & $\begin{array}{l}\text { Maintaining a sound environment for human activities } \\
\text { by resource management and pollution control. }\end{array}$ \\
\hline
\end{tabular}

all the others at various structural and functional levels (Alberti and Marzluff, 2004). According to ecological principles, urban ecosystems also can be classified as functions of production, consumption and restoration (Table 2). These functions need to be supported by many material flows. These material flows affect the quantity and quality of the functions. They are also the linkage between urban and natural ecosystems. According to the MFA view, the material flow process can be described as input-useoutput (Fig. 1). In light of feedback information, input and output quantities can be controlled by adjusting the economic model and consumption structure. For example, through waste recycling and sustainable consumption, the quantity of output 2 can be increased and that of output 1 can be decreased, which will release the stress on the eco-environment. To maintain the health of an urban ecosystem, the natural ecosystem should be considered when planning the scale, speed, intensity and distribution of anthropogenic development.

With its functions operating, an urban ecosystem can obtain materials and energy and can control pollution. Therefore, functions drive the material flows and determine their quality and quantity, which can reflect the health status of an urban ecosystem. For this reason we can analyze the status of the functions by using material flow perspectives. The health diagnosis focuses on resource efficiency and pollution control during the material flow process incorporating input, use and output.

\subsection{Material flow between natural and urban ecosystems}

In natural ecosystems, healthy material flow is established through long-term intricate material cycling that maintains a balance among producers, consumers and decomposers. When the material flows of an urban ecosystem involve that of a natural ecosystem, this balance is interrupted. Two aspects show the interaction between the two systems: resource input and waste output. Resources include any resource that is required for urban development, such as land, forests, minerals, and fossil fuels. Resource exploitation affects regeneration and resource reserves, which are the source of material flow. Excessive resource exploitation can cause resource shortages and decrease biological diversity. On the other hand, waste output affects the environmental carrying capacity, which is the sink of material flow. If the waste is excessive or foreign to the environment, waste output can lead to environmental pollution and ecological degradation. Therefore, it is vital to maintain a healthy material cycle for the two ecosystems to support ecosystem function.

In the material cycle, the materials include substances and goods (Brunner and Rechberger, 2004). A substance is any (chemical) element or compound composed of uniform units. Elements are divided into three groups according to their percent composition in the biosphere (Dickinson and Murphy, 1998): the major nutrients, the macronutrients and the micronutrients. The major nutrients are hydrogen, oxygen and carbon, which account for about $99.4 \%$ of the composition of the biosphere.
These materials enter the urban ecosystem through human consumption of fossil fuels, minerals, organism and water. Fossil fuels include oil, coal and natural gas; minerals include all kinds of metal and non-metallic materials; and organism includes wood and agricultural products, etc. These resources support urban functions such as industry, agriculture, transportation, business, residential living, education, health, finance and entertainment. After its use by urban ecosystem, some of the materials are discharged into the natural ecosystem as waste and enter the material cycle. If some are present in excess or are foreign to nature, this can lead to serious environmental pollution. Fortunately, urban ecosystems have a restoration function and can manage waste discharge by waste recycling and waste treatment. Generally, there are many material flows in an urban ecosystem from resource input to waste output (Fig. 2). Healthy flows have circular characteristics; while unhealthy flows have linear characteristics. Unhealthy material flows from urban ecosystems interrupt the material cycle of natural ecosystems.

\subsection{Water cycle}

In an urban ecosystem, water is used not only for drinking, but also as a raw material, as a carrier for transporting materials and energy, for entertainment and for irrigation, etc. Water entering the urban ecosystem is also involved in the hydrological cycle of the natural ecosystem. Surface and ground water resources are the main supplies for households, industry and commercial uses. After use, domestic and industrial waste waters flow into the river or ocean. Urban ecosystems affect the water cycle in two ways. The first is water pollution, which leads to a deterioration in water quality, affecting not only water use, but also the aquatic ecosystem. The second is water shortages. Population growth and industrial development increase the demand for water, resulting in a shortage of water. Therefore, water shortages and water pollution of urban ecosystems are defined as symptoms of an unhealthy urban ecosystem, as shown in Fig. 3.

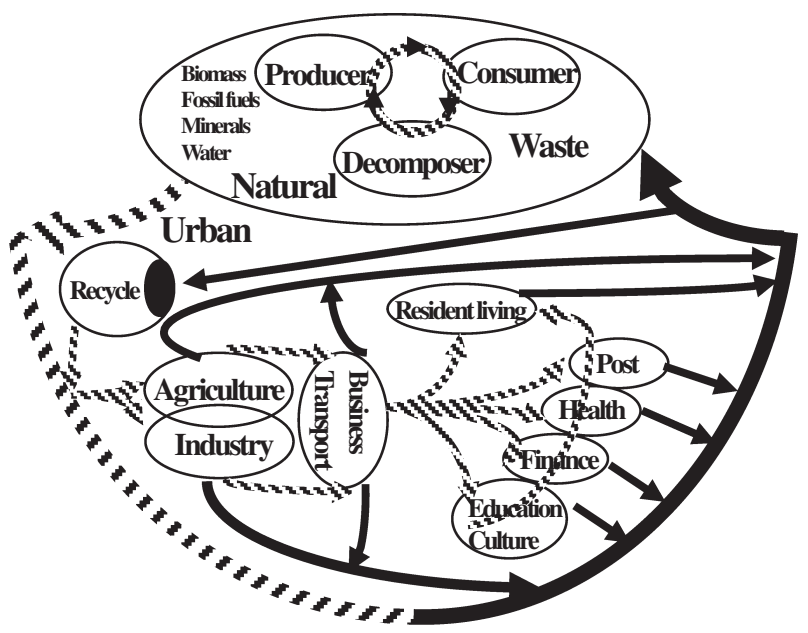

Fig. 2. Material flows between the urban and the natural ecosystem. There are many material flows in an urban ecosystem, for example, the flows among industry, agriculture and service. The striped line represents raw material flows or product flows and the black line represents waste flows. These flows involve in the material cycle of the natural ecosystem (among producers, consumers and decomposers). The urban ecosystem disturbs the material flow of the natural ecosystem by unhealthy flows of excessive resource acquisition (biomass, fossil fuels, minerals and water) and of excessive waste discharge. The three R principles (Reduce, Reuse and Recycle) will help to maintain a healthy material flow and to facilitate sustainable development of both the urban and the natural ecosystem. 


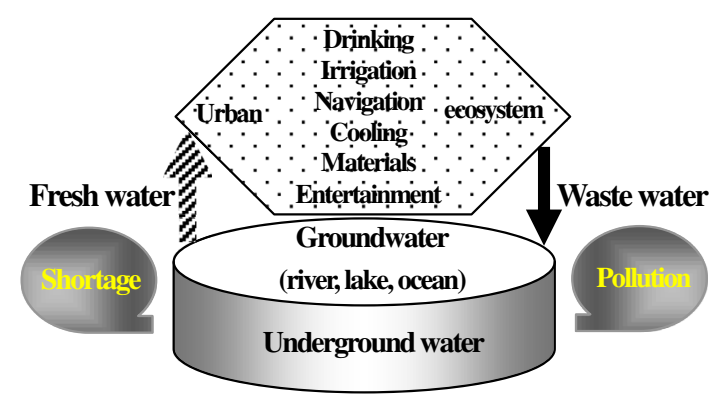

Fig. 3. Urban hydrological cycle. Excessive use and discharge cause an unhealthy urban ecosystem. The symptoms are water shortages and water pollution.

\subsection{Carbon cycle}

Carbon is one of the main elements in organisms and is essential for life. Green plants, including terrestrial and aquatic plants, absorb carbon dioxide from the atmosphere through photosynthesis, change it into sugars, cellulose and proteins, and thus assimilate carbon as biomass. Carbon can be transferred through the food chain among plants and animals and can be dissipated into the atmosphere again through decomposition by microorganisms. If the bodies of plants and animals sink to the bottom of a water body or underground, the carbon in them leaves the carbon cycle. After geological aging, some carbon can be exposed on the surface as carbonate rocks and coral reefs. Carbon in the lithosphere can return to the atmosphere through weathering, solvation and volcanic explosion. Some can be changed into fossil fuels, which are the main energy for urban development.

Human activities over the past two centuries have modified the carbon cycle, as shown in Fig. 4. Carbon entering urban ecosystems is mainly from fossil fuels, raw materials, and foods. Carbon reentry into the natural ecosystem is mainly through emissions from energy consumption, industrial processes, food consumption, waste disposal and land-use change. Raw materials are processed into products. Carbon in raw materials returns to the natural ecosystem as GHG or waste. If some of these wastes are foreign to the natural environment or if the quantity of waste is excessive, reentry into the original carbon cycle can be difficult. This situation often causes serious environmental problems that affect the healthy development of urban ecosystems. Fossil fuels are the main energy source and represent one of the main carbon sources of urban ecosystems. Burning of fossil fuels discharges more GHG into the atmosphere, which is one of the main causes of climate change. Therefore, a modified carbon cycle is also a factor that affects the healthy development of urban ecosystems.

According to the above discussion, the material cycle between urban and natural ecosystems is important for the health of urban ecosystems. To support ecosystem functions, material cycles for the urban ecosystem should coordinate with the natural ecosystem. In other words, resource exploitation should not exceed the quantity available in the natural ecosystem, and the quantity of wastes discharged from the urban ecosystem should not exceed the carrying capacity of the natural ecosystem to assimilate these wastes. To achieve this balance, diagnosis of the input and output of resources is crucial to maintaining a healthy cycle and thus good urban ecosystem health.

\section{Framework for diagnosis of urban ecosystem health}

\subsection{Model for urban ecosystem health}

In this study we consider a healthy urban ecosystem to be a system that has functions normally and has an expected normal resilience to ecological environmental problems. Normal functioning refers to the functioning that a system has when the system isn't damaged. Normal resilience refers to the restoration ability that a system has when the system isn't collapsed. A healthy material flow can support a system operating with sound functions. Therefore, material flow can be regarded as the "lifeblood" of an urban ecosystem and can reflect its health. A model based on material cycling can be used to diagnose the health of an urban ecosystem.

According to the discussion above, a natural ecosystem is not only a pool of resources, but is also a pool for purifying pollutants from urban ecosystems. There is the material chain comprised of input-utilization-output between natural and urban ecosystems. As the natural ecosystem is at the beginning and end of the chain, the chain becomes a loop involving the material cycle of the natural ecosystem. During the cycle, the urban ecosystem first obtains materials from the natural ecosystem. Then, depending on the technological conditions, economic structure and consumption patterns, the materials are distributed and utilized through production and development of the urban ecosystem. Finally, wastes are discharged into the natural ecosystem. A suitable pattern of material use can improve the efficiency of material cycling of an urban ecosystem. The economic structure and consumption

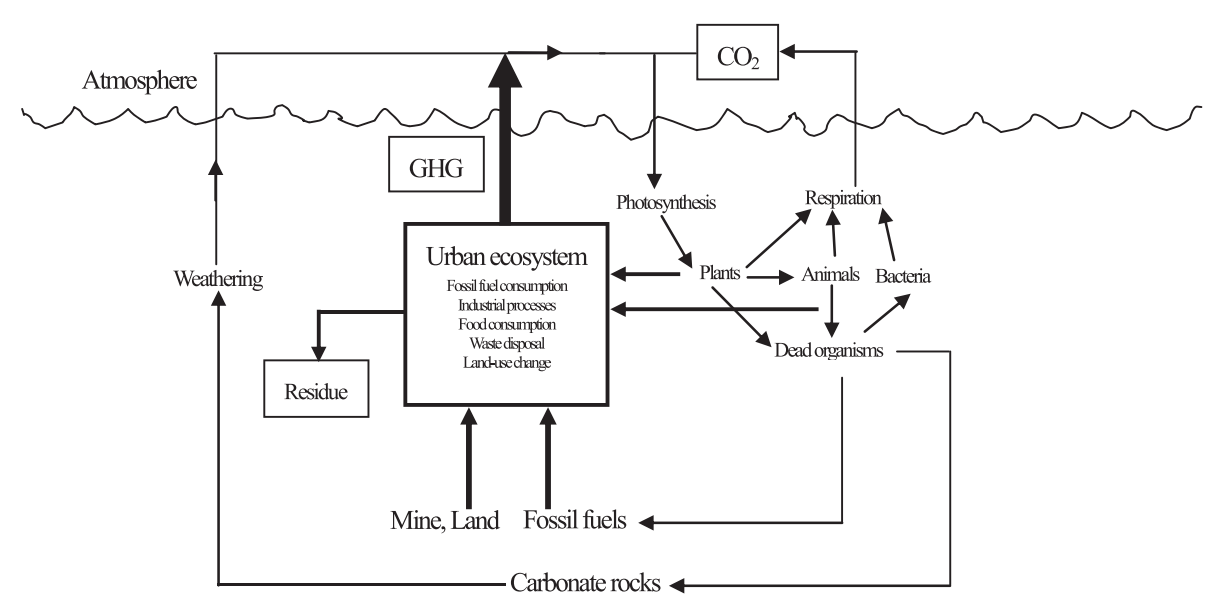

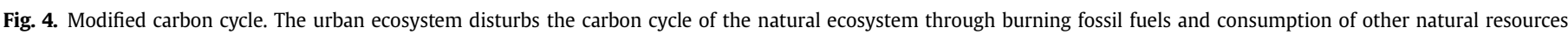
(plant, animal, mineral). 


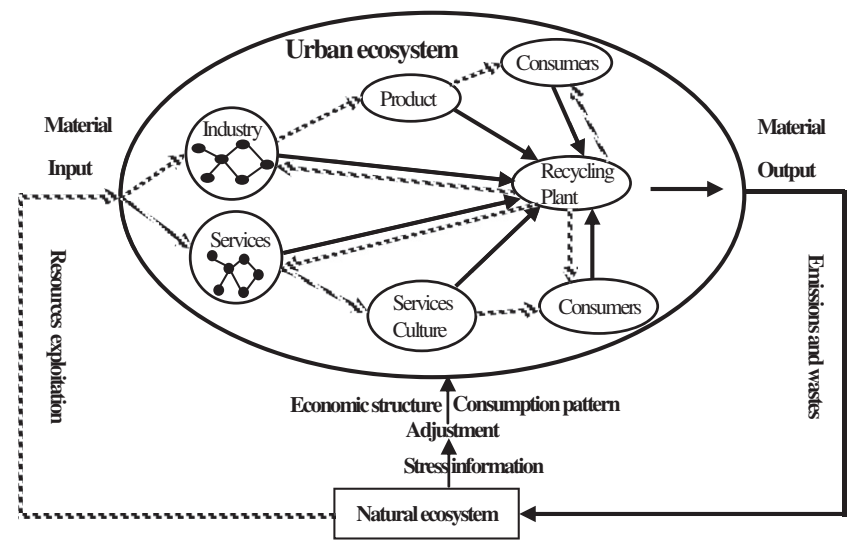

Fig. 5. A diagnosis model for urban ecosystem health. There are many kinds of flows among the subsystems of an urban ecosystem such as industry, agriculture, commercial, residential consumer, and recycling systems. The striped line represents raw material flows and product, and the black line represents waste flows. Rational material flow can relieve environmental stress. Urban ecosystem health can be diagnosed by analyzing the material input flow and material output flow. Rational material flows by adjusting economic structure and consumption patterns can help recover urban ecosystem health.

attributes determine the pattern of material use. Therefore, stress imposed on the natural ecosystem can be relieved by adjusting the economic structure and consumption patterns.

We established a model based on the cycling mechanism (Fig. 5) comprised of five parts: the natural pool, material input, material utilization in urban ecosystem, material output, and adjustment incentives. From material input to output, there are many kinds of material flows among the subsystems such as industry, services (e.g., transportation, business, education, healthcare, finance, and post) and recycling systems. Recycling systems play a key role for maintaining healthy material flow in urban ecosystem. Rational material flows can relieve environmental stress. By addressing input flow and output flow, the model can reflect whether the degree of resource exploitation is within the ecological threshold and whether waste discharge is within the environmental carrying capacity. Thus, the health of an urban ecosystem can be diagnosed.

\subsection{Diagnosis indices and approach}

Using the model described above, we developed a framework to diagnose the health of urban ecosystems. We integrated all effect factors at a functional level and diagnosed the health of an urban ecosystem through analysis of resource utilization and residue release. The framework is comprised of four aspects: function analysis, material flow input and output analysis, health diagnosis, and function optimization as shown in Fig. 6.

In the function analysis we determined the system boundary first, and then identified the functions of an urban ecosystem and the relationship between material flow and these functions. Generally, there are three main functions including producing, consuming, and controlling of pollution for an urban ecosystem. For the producing function, we considered the process and efficiency of resource flow in each enterprise for each industry, as well as their environmental impact during the process. For the consuming function, we focused on the analysis of municipal waste and its disposal. For the controlling of pollution, we focused on the environmental quality analysis (environmental effect).

In input flow-output flow analysis, we analyzed resource flow and residue release for each enterprise, municipal waste disposal and environmental quality for the city. The relative degree of resource consumption is given by $R_{i j}=X_{i j} / Y_{j}$, where $R_{i j}$ is the degree of consumption of resource $i$ for product $j$ from enterprise $A, X_{i j}$ is the input quantity of resource $i$ for product $j$ from enterprise $A$, and $Y_{j}$ is the output or output value of product $j$ for enterprise $A$. The environmental load of residue $i$ is given by $E_{k j}=W_{k j} / Y_{j}$, where $E_{k j}$ is the environmental load of residue $k$ for product $j$ from enterprise $A$ and $W_{k j}$ is the discharge quantity of residue $k$ for product $j$ from enterprise $A$. Where $\lambda_{\mathrm{f}}$ is the rate of healthy enterprises, $N_{\mathrm{h}}$ is the number of healthy enterprises, and $N_{\mathrm{t}}$ is the total number of enterprises, then $\lambda_{\mathrm{f}}=\left(N_{\mathrm{h}} / N_{\mathrm{t}}\right) \times 100 \%$. Where $\lambda_{\mathrm{w}}$ is the disposal rate for municipal waste, $Q_{d}$ is the disposal quantity of municipal waste and $Q_{t}$ is the total quantity of municipal waste, then $\lambda_{w}=\left(Q_{d} / Q_{t}\right) \times 100 \%$. Where $\lambda_{\mathrm{e}}$ is the standard-meeting rate for urban environmental function zones, $N_{\mathrm{S}}$ is the standard-meeting number of environmental function zones, and $N_{\mathrm{t}}$ is the total number of environmental function zones, then $\lambda_{\mathrm{e}}=\left(N_{\mathrm{s}} / N_{\mathrm{t}}\right) \times 100 \%$. Table 3 lists parameters

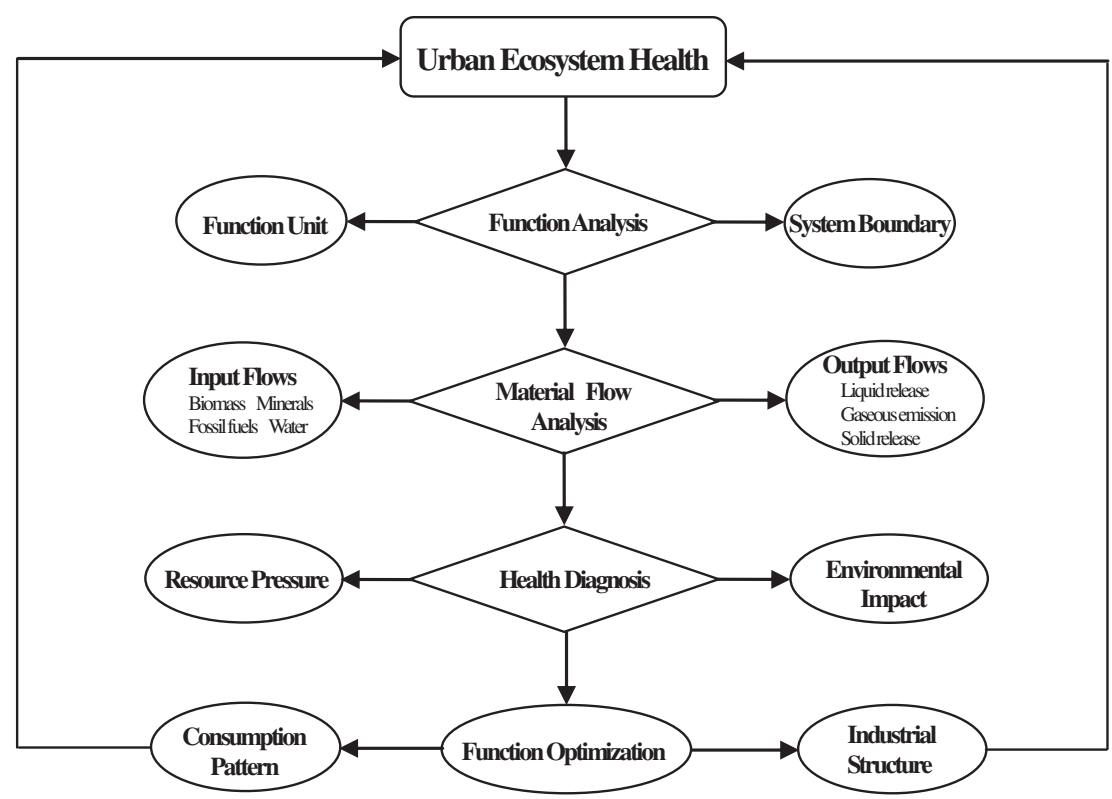

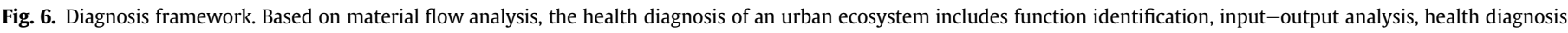
and function optimization. 
Table 3

Input-output analysis for urban ecosystems.

\begin{tabular}{lllll}
\hline Name & $\begin{array}{l}\text { Resource } \\
\text { input }\end{array}$ & $\begin{array}{l}\text { Production } \\
\text { output }\end{array}$ & $\begin{array}{l}\text { Residue } \\
\text { release }\end{array}$ & $\begin{array}{l}\text { Discharge } \\
\text { location }\end{array}$ \\
\hline Enterprise 1 & $X_{11} \ldots X_{i j}$ & $Y_{1} \ldots Y_{j}$ & $W_{11} \ldots W_{k j}$ & $D_{11} \ldots D_{k h}$ \\
Enterprise 2 & $X_{11 \ldots X_{i j}}$ & $Y_{1} \ldots Y_{j}$ & $W_{21} \ldots W_{k j}$ & $D_{11} \ldots D_{k h}$ \\
$\ldots$ & $\ldots$ & $\ldots$ & $\ldots$ & $\ldots$ \\
Enterprise $A$ & $X_{11} \ldots X_{i j}$ & $Y_{1} \ldots Y_{j}$ & $W_{n 1} \ldots W_{k j}$ & $D_{11} \ldots D_{k h}$ \\
Indicator 1 & $R_{i j}=X_{i j} / Y_{j}$ & & & \\
Indicator 2 & $E_{k j}=W_{k j} / Y_{j}$ & & \\
Indicator 3 & $\lambda_{\mathrm{f}}=\left(N_{\mathrm{h}} / N_{\mathrm{t}}\right) \times 100 \%$ & & \\
Indicator 4 & $\lambda_{\mathrm{w}}=\left(Q_{\mathrm{d}} / Q_{\mathrm{t}}\right) \times 100 \%$ & & \\
Indicator 5 & $\lambda_{\mathrm{e}}=\left(N_{\mathrm{s}} / N_{\mathrm{t}}\right) \times 100 \%$ & & \\
\hline
\end{tabular}

such as the resource input $(X)$ and product output or output value $(Y)$ for each enterprise, the residue release (waste discharge, $W$ ) and discharge location $(D)$, and three rates $\left(\lambda_{\mathrm{f}}, \lambda_{\mathrm{w}}\right.$ and $\left.\lambda_{\mathrm{e}}\right)$.

Theoretically, we propose three categories for diagnosis of health: healthy, sub-healthy and unhealthy, as shown in Table 4. A healthy status indicates that the resource demand of an urban ecosystem is within the maximum possible amount of resources available and waste discharge is within the environmental carrying capacity. A sub-healthy status indicates that resource demand exceeds the maximum resource availability but is within the ecological threshold, and waste discharge is within but close to the environmental carrying capacity. An unhealthy status indicates that resource demand exceeds the ecological threshold and waste discharge exceeds the environmental carrying capacity, so the system tends to break down because of resource shortages and environmental pollution.

In practice, it is difficult to calculate the ecological threshold for resource use for an urban ecosystem (Carpenter et al., 2005). However, we can use national cleaner production standards for the product function health diagnosis and use environmental standards for the environmental quality diagnosis. The paper suggests the following five parameters: (1) $P$, the national advanced standard for resource consumption per unit product; (2) $N$, the national basic standard for resource consumption per unit product; (3) $S$, the national advanced standard for pollutant emission per unit product; (4) $M$, the national basic standard for pollutant emission per unit product; and (5) $C_{\mathrm{T}}$, the permissible discharge of the pollutant for each enterprise under total quantity control. Here, $P<N$ and $S<M$. The indicator system based on cleaner production is listed in Table 5.

Based on the above discussion, urban ecosystem health can be reflected by the health status of material input and output, which can be estimated in terms of the health of resource use, the health of waste discharge of enterprises, the health of municipal consumption and environmental health. Therefore the diagnosis of urban ecosystem health is based on three aspects including production status, consumption status and environmental status. We propose the following situations in Table 4. For a healthy enterprise production, resource consumption and waste discharge reach the national advanced standards, and total waste discharge reaches permissible discharge, then $R_{i j}<P, E_{k j}<S$, and $W_{k}<C_{\mathrm{T}}$. For a subhealthy enterprise production, resource consumption and waste discharge exceed the national advanced standards but reach national basic standards, and total waste discharge also reaches permissible discharge, them $P<R_{i j}<N, S<E_{k j}<M$, and $W_{k}<C_{\mathrm{T}}$. For an unhealthy enterprise production, resource demand and waste discharge exceed national basic standards, and total waste discharge exceeds permissible discharge, then $R_{i j}>N, E_{k j}>M$, and/ or $W_{k}>C_{\mathrm{T}}$.

Therefore, we propose to diagnose urban ecosystem health by three functions, including production function, municipal consumption and environmental protection. However, there is no clear boundary between healthy and unhealthy. Here, we use the cut off points of above $90 \%, 90-80 \%$ and below $80 \%$. For a healthy production function, the healthy enterprise rate $\left(\lambda_{\mathrm{f}}\right)$ should be more than $90 \%$; for a sub-healthy production function, the healthy enterprise rate would be between $80 \%$ and $90 \%$; for an unhealthy production function, the rate would be less than $80 \%$. For a healthy municipal consumption, the waste disposal rate $\left(\lambda_{\mathrm{w}}\right)$ would exceed $90 \%$. For a sub-healthy municipal consumption, the waste disposal rate would be between $80 \%$ and $90 \%$. For an unhealthy municipal consumption, the waste disposal rate would be less than $80 \%$. For a healthy environment, the standard-meeting rate for environmental quality $\left(\lambda_{\mathrm{e}}\right)$ would be more than $90 \%$; for a sub-healthy environment, the rate would be within $80 \%$ and $90 \%$; for an unhealthy environment, the rate would be less than $80 \%$.

The diagnosis results are expressed in terms of the percentage of healthy enterprises and the rate of municipal solid waste disposal, as well as the standard-meeting rate of environmental quality. The result reflects not only the health of functions of resource consumption by enterprises and households, but also of environmental quality. This approach can be used to identify how many enterprises are healthy, sub-healthy and unhealthy, the degree of municipal solid waste disposal, and the environmental quality status. This information will help decision-makers to formulate more suitable strategies for urban ecosystem health.

As water is a special resource, we suggest the following method for diagnosing health of the water cycle (Table 6). Let $F$ be the water demand for a city, $T$ be the total water supply amount available (including local and other places), $L$ be the local supply amount, $G$ be the discharge amount of a pollutant, $C$ be the environmental

Table 4

Health diagnosis categories and criteria for urban ecosystems.

\begin{tabular}{|c|c|c|c|c|c|c|}
\hline Category & Description & $\begin{array}{l}\text { Enterprise } \\
\text { status }\end{array}$ & $\begin{array}{l}\text { Production }\left(\lambda_{\mathrm{f}}\right) \\
\text { (rate of healthy } \\
\text { enterprise) }\end{array}$ & $\begin{array}{l}\text { Consumption }\left(\lambda_{\mathrm{w}}\right) \\
\text { (rate of municipal } \\
\text { waste disposal) }\end{array}$ & $\begin{array}{l}\text { Environment } \\
\left(\lambda_{\mathrm{e}}\right) \text { (standard- } \\
\text { meeting rate) }\end{array}$ & Urban health diagnosis \\
\hline Healthy & $\begin{array}{l}\text { Resource demand within the maximum } \\
\text { amount available; waste discharge is } \\
\text { within the environmental carrying capacity }\end{array}$ & $\begin{array}{l}\text { Running efficiently } \\
R_{i j}<P \text { and } E_{k j}<S \\
\Sigma W_{k}<C_{\mathrm{T}}\end{array}$ & $>90 \%$ & $>90 \%$ & $>90 \%$ & \multirow{3}{*}{$\begin{array}{l}\text { 1. The percentage of } \\
\text { healthy, sub-healthy and } \\
\text { unhealthy enterprises, } \\
\text { 2. The healthy degree of } \\
\text { municipal solid waste } \\
\text { disposal, } \\
\text { 3. The standard-meeting } \\
\text { rate of urban environmental } \\
\text { function zone. }\end{array}$} \\
\hline $\begin{array}{l}\text { Sub- } \\
\text { healthy }\end{array}$ & $\begin{array}{l}\text { Resource demand exceeds the maximum } \\
\text { amount available but within the ecological } \\
\text { threshold; waste discharge close to the } \\
\text { environmental carrying capacity }\end{array}$ & $\begin{array}{l}\text { Running at low efficiency } \\
P<R_{i j}<N \text { or } S<E_{k j}<M \\
\Sigma W_{k}<C_{\mathrm{T}}\end{array}$ & $80-90 \%$ & $80-90 \%$ & $80-90 \%$ & \\
\hline Unhealthy & $\begin{array}{l}\text { Resource demand exceeds the ecological } \\
\text { threshold; waste discharge exceeds the } \\
\text { environmental carrying capacity }\end{array}$ & $\begin{array}{l}\text { System tends to break } \\
\text { down } \\
R_{i j}>N \text { or } E_{k j}>M \\
\Sigma W_{k}>C_{\mathrm{T}}\end{array}$ & $<80 \%$ & $<80 \%$ & $<80 \%$ & \\
\hline
\end{tabular}


Table 5

Diagnosis indicator system based on cleaner production.

\begin{tabular}{lll}
\hline Category & Indicators & Criteria \\
\hline Resource use & $\begin{array}{l}\text { Water use } \\
\text { Energy use } \\
\text { Raw material consumption }\end{array}$ & $\begin{array}{l}\text { National standard for } \\
\text { cleaner production }\end{array}$ \\
Pollution discharge & $\begin{array}{l}\text { Monitoring indicators } \\
\text { for waste air }\end{array}$ & $\begin{array}{l}\text { National standard for } \\
\text { cleaner production }\end{array}$ \\
& $\begin{array}{l}\text { Monitoring indicators } \\
\text { for waste water }\end{array}$ & \\
Waste recycling & Waste water & National standard for \\
& Waste solid & cleaner production \\
& Waste air & \\
\hline
\end{tabular}

carrying capacity for the pollutant, and $K$ be the maximal permissible discharge. In a healthy water cycle, the water demand is within the local supply amount and the discharge amount of a pollutant is within the environmental carrying capacity $(F<L$ and $G<C$ ). In a sub-healthy water cycle, the water demand exceeds the local supply but is within the total water supply and the discharge amount of a pollution exceeds the carrying capacity of environment but is within the maximal permissible discharge $(L<F<T$ and $C<G<K$ ). In an unhealthy water cycle the water demand exceeds the supply and pollutant discharge exceeds the maximal permissible level, so there are water shortages and water pollution problems $(L>T$ and $G>K)$.

Because the diagnosis results can identify unhealthy enterprises, unhealthy consumption, and unhealthy environment, they may give clear diagnosis guides for function optimization. Therefore, decision-makers can adopt suitable strategies to adjust the economic structure and consumption patterns for sustainable urban development.

\section{Analysis and discussion}

\subsection{Health of urban ecosystem}

For illustrating the method we developed, this section will give a case study for the health analysis of an urban ecosystem. The city (Wuhan) is a large city with a population of approximately 9 million in Central China and covers an area of approximately $8220 \mathrm{~km}^{2}$. It is the center of industries and the hub of transportation in Central China. It is facing great challenges for integrating economic development and environmental protection. For achieving that aim, maintaining urban ecosystem health is crucial; diagnosing health problems can help decision makers create sound strategies for sustainable development. According to our approach, the urban ecosystem health diagnosis includes production function diagnosis, consumption function diagnosis and environmental quality diagnosis. Although data are not available for a complete diagnosis of the health of an urban ecosystem, we can analyze the health of part of an urban ecosystem to validate our approach. In this case study, the production function diagnosis includes pulp and paper, iron and steel, and crude oil processing industry. The result is shown in Table 7 . The data come from census data of pollution sources, an information bulletin on solid waste pollution and prevention, and a bulletin on environmental quality of the city, all from 2007.

The results show that, for the production function, according to the national cleaner production standards (CPS), the assessment indicators include three categories including resource use, pollution emission and waste recycling (see Table 7). The resource use index included water use, energy consumption and raw material consumption; the pollution discharge index included waste water, $\mathrm{BOD}, \mathrm{COD}, \mathrm{SO}_{2}$, smoke dust, petroleum, volatile phenol; the waste recycling index included waste water. In light of the assessment method and criteria suggested above, the urban healthy status was diagnosed as following (Fig. 7): Production function was unhealthy, as the average healthy rate of resource use was $56 \%$, the average healthy rate of pollution emission was 76\%, and the average healthy rate of waste recycling was $13 \%$. The overall consumption function was healthy, with an average disposal rate of solid waste of $93 \%$, though the disposal rate of living solid waste was sub-healthy (80\%). Environmental quality was unhealthy, with an average standard-meeting rate of environmental function zone for air quality at $70 \%$, with the $\mathrm{SO}_{2}$ standard-meeting rate being the highest $(100 \%)$ and the $\mathrm{PM}_{10}$ standard-meeting rate being the lowest (44\%). The standard-meeting rate of environmental function zone for water quality was $42 \%$, with the river standard-meeting rate of environmental function zone at $64 \%$ and the lake standard-meeting rate of environmental function zone at $20 \%$.

From the analysis data above, we know that the air and water quality of the city were both unhealthy. One of the main reasons is that pollutant discharge exceeded the environmental capacity. Based on the data analyzed above, the pollutants came from three types of the enterprises. One was the enterprises in which resource use efficiency was unhealthy, which accounts for about $41 \%$; Another was the enterprises in which pollution emissions were unhealthy and these accounted for about 31\%. The last was the enterprises in which the waste water recycling was unhealthy and these accounted for about $86 \%$. Living solid waste was also the main pollution source. Our method provides a bridge between making a healthy diagnosis and making decisions. The bridge can help the decision maker find the health problems and make practical and available strategies to solve the problems. Therefore, priority strategies for maintaining urban health are improving resource use rate, total pollution emission control, enhancing waste water and living solid waste treatment and recycling.

\subsection{Health of a water cycle}

We used the water cycle for Tianjin in 2002 as a case study for the health of a water cycle. Tianjin is a large city with a population

Table 6

Health diagnosis categories for water resource.

\begin{tabular}{|c|c|c|}
\hline Category & Description & System status \\
\hline Healthy & $\begin{array}{l}\text { Water demand }(F) \text { is within the local water supply }(L) \\
\text { Pollutant discharge }(G) \text { is within the environmental carrying capacity }(C)\end{array}$ & $\begin{array}{l}\text { Sufficient water resources and good water quality } \\
F<L \text { and } G<C\end{array}$ \\
\hline Sub-healthy & $\begin{array}{l}\text { Water demand exceeds local supply but is within the total water supply }(T) \\
\text { Pollutant discharge exceeds the environmental carrying capacity but is } \\
\text { within the maximal permissible discharge limit }(K)\end{array}$ & $\begin{array}{l}\text { Water demand is just met by supply } \\
\text { Water quality is moderate, with mild pollution } \\
L \leq F \leq T \text { and } C \leq G \leq K\end{array}$ \\
\hline Unhealthy & $\begin{array}{l}\text { Water demand exceeds total water supply }(T) \\
\text { Pollution levels exceed the maximal permissible discharge }(K)\end{array}$ & $\begin{array}{l}\text { Water shortages and serious pollution } \\
F>T \text { and } G>K \text {; or each of them }\end{array}$ \\
\hline
\end{tabular}


Table 7

Health diagnosis for urban ecosystem health.

\begin{tabular}{|c|c|c|c|c|c|c|c|c|c|c|c|}
\hline \multirow[t]{2}{*}{ Items } & & & \multicolumn{6}{|c|}{ Production function $^{\mathrm{a}}\left(\lambda_{\mathrm{f}}\right)$} & \multirow[t]{2}{*}{$\begin{array}{l}\text { Consumption } \\
\text { function }^{\mathrm{b}}\left(\lambda_{\mathrm{w}}\right)\end{array}$} & \multicolumn{2}{|c|}{$\begin{array}{l}\text { Environmental } \\
\text { health }^{\mathrm{c}}\left(\lambda_{\mathrm{e}}\right)\end{array}$} \\
\hline & & & $\begin{array}{l}\text { Pulp and } \\
\text { paper }\end{array}$ & Average & $\begin{array}{l}\text { Iron and } \\
\text { steel }\end{array}$ & Average & $\begin{array}{l}\text { Crude oil } \\
\text { processing }\end{array}$ & Average & & Air & Water \\
\hline \multirow[t]{11}{*}{ Healthy } & Resource & Water use & $68.6 \%$ & $78 \%$ & 61.3 & $52 \%$ & $51.8 \%$ & $38 \%$ & 93\% (disposal rate & & \\
\hline & use & $\begin{array}{l}\text { Energy } \\
\text { consumption }\end{array}$ & $88.6 \%$ & & $73 \%$ & & $60.7 \%$ & & of solid waste in 2007) & & \\
\hline & & $\begin{array}{l}\text { Raw material } \\
\text { consumption }\end{array}$ & $77.1 \%$ & & $20 \%$ & & 0 & & & & \\
\hline & Pollution & Waste water & $68.6 \%$ & $71 \%$ & $70 \%$ & $76 \%$ & $46.4 \%$ & $81 \%$ & $93 \%$ (disposal rate of & & \\
\hline & discharge & BOD & $71.5 \%$ & & - & & - & & Industrial solid waste & & \\
\hline & & COD & $74.3 \%$ & & $100 \%$ & & $81.5 \%$ & & in 2007) & & \\
\hline & & $\mathrm{SO}_{2}$ & & & $56.5 \%$ & & - & & $99 \%$ (disposal rate of & & \\
\hline & & Smoke dust & & & $53.5 \%$ & & - & & industrial dangerous & & \\
\hline & & Petroleum & & & $100 \%$ & & $96.3 \%$ & & waste in 2007) & & \\
\hline & & Volatile phenol & & & & & $100 \%$ & & $\begin{array}{l}100 \% \text { (disposal rate of } \\
\text { medical waste in } 2007 \text { ) }\end{array}$ & & \\
\hline & $\begin{array}{l}\text { Waste } \\
\text { recycling }\end{array}$ & Waste water & $5.7 \%$ & $6 \%$ & $20 \%$ & $20 \%$ & - & & & & \\
\hline \multirow[t]{11}{*}{ Sub-healthy } & Resource & Water use & $2.9 \%$ & $1 \%$ & $6.5 \%$ & $3 \%$ & $14.8 \%$ & $6 \%$ & & & \\
\hline & use & Energy consumption & 0 & & $3.8 \%$ & & $3.6 \%$ & & & & \\
\hline & & $\begin{array}{l}\text { Total material } \\
\text { consumption }\end{array}$ & 0 & & 0 & & 0 & & & & \\
\hline & Pollution & Waste water & 0 & $1 \%$ & 0 & $4 \%$ & $14.3 \%$ & $5 \%$ & $80 \%$ (disposal rate of & & \\
\hline & discharge & BOD & 0 & & - & & - & & living solid waste & & \\
\hline & & COD & $2.9 \%$ & & 0 & & $3.7 \%$ & & in 2007) & & \\
\hline & & $\mathrm{SO}_{2}$ & & & $13 \%$ & & - & & & & \\
\hline & & Smoke dust & & & $7.1 \%$ & & - & & & & \\
\hline & & Petroleum & & & 0 & & 0 & & & & \\
\hline & & Volatile phenol & & & & & 0 & & & & \\
\hline & $\begin{array}{l}\text { Waste } \\
\text { recycling }\end{array}$ & $\begin{array}{l}\text { Waste water } \\
\text { recycling rate }\end{array}$ & 0 & 0 & $3.3 \%$ & $3 \%$ & - & & & & \\
\hline \multirow[t]{11}{*}{ Unhealthy } & Resource & Water use & $28.6 \%$ & $21 \%$ & $32.3 \%$ & $45 \%$ & $33.3 \%$ & $56 \%$ & & & \\
\hline & consumption & $\begin{array}{l}\text { Energy } \\
\text { consumption }\end{array}$ & $11.4 \%$ & & $23.1 \%$ & & $35.7 \%$ & & & & \\
\hline & & $\begin{array}{l}\text { Material } \\
\text { consumption }\end{array}$ & $22.9 \%$ & & $80 \%$ & & $100 \%$ & & & & \\
\hline & Pollution & Waste water & $31.4 \%$ & $28 \%$ & $30 \%$ & $20 \%$ & $39.3 \%$ & $14 \%$ & & $70 \%$ & $64 \%$ (river) \\
\hline & discharge & BOD & $28.6 \%$ & & - & & - & & & $44 \%\left(\mathrm{PM}_{10}\right)$ & $20 \%$ (lake) \\
\hline & & COD & $22.9 \%$ & & 0 & & $14.8 \%$ & & & $100 \%\left(\mathrm{SO}_{2}\right)$ & \\
\hline & & $\mathrm{SO}_{2}$ & & & $30.4 \%$ & & - & & & $66 \%\left(\mathrm{NO}_{2}\right)$ & \\
\hline & & Smoke dust & & & $39.3 \%$ & & - & & & & \\
\hline & & Petroleum & & & 0 & & $3.7 \%$ & & & & \\
\hline & & Volatile phenol & & & & & 0 & & & & \\
\hline & $\begin{array}{l}\text { Waste } \\
\text { recycling }\end{array}$ & Waste water & $94.3 \%$ & $94 \%$ & $76.7 \%$ & $77 \%$ & - & & & & \\
\hline $\begin{array}{l}\text { Urban } \\
\text { health } \\
\text { diagnosis }\end{array}$ & & & & & $\begin{array}{l}\text { Production } \\
\text { function: } \\
\text { Resource } \\
\text { use (56\%) } \\
\text { Pollution } \\
\text { discharge } \\
\text { (76\%) } \\
\text { Waste } \\
\text { recycling } \\
(13 \%)\end{array}$ & & & & & & \\
\hline
\end{tabular}

a The data come from 2007 census data of pollution sources of the city.

b The data come from the solid waste pollution and prevention 2007 information bulletin of the city.

c The data come from the environmental quality 2007 bulletin of the city.

of 10.113 million in northern China and covers an area of approximately $10,000 \mathrm{~km}^{2}$. The city suffers from water shortages. According to statistical data, the water available per capita per year is only about 152 cubic meters, which is only approximately one-third of the per capita share of the lower water warning limit (500 cubic meters per year) of the United Nations recommendations. Thus, the hydrologic system of Tianjin is very fragile. However, a healthy hydrologic system is very important for development of Tianjin.

A healthy water cycle depends on water supply and water quality. Data for Tianjin in 2002 are listed in Table 8. Water demand $\left(19.6 \times 10^{8} \mathrm{~m}^{3}\right)$ was less than the total supply $\left(19.96 \times 10^{8} \mathrm{~m}^{3}\right)$ but exceeded the local supply $\left(13.34 \times 10^{8} \mathrm{~m}^{3}\right)$. Thus, although the local water supply cannot meet demand in Tianjin, water supply from other locations was used to resolve this problem. Therefore, the water supply was in a sub-healthy situation. This highlights the necessity of protecting water resources and improving the efficiency of water utilization to support development in Tianjin. We used data on COD and ammonia nitrogen discharge for output analysis. In 2002, with a $90 \%$ hydrological guarantee, the environmental carrying capacity in Tianjin for COD and ammonia nitrogen was 30,340 and 

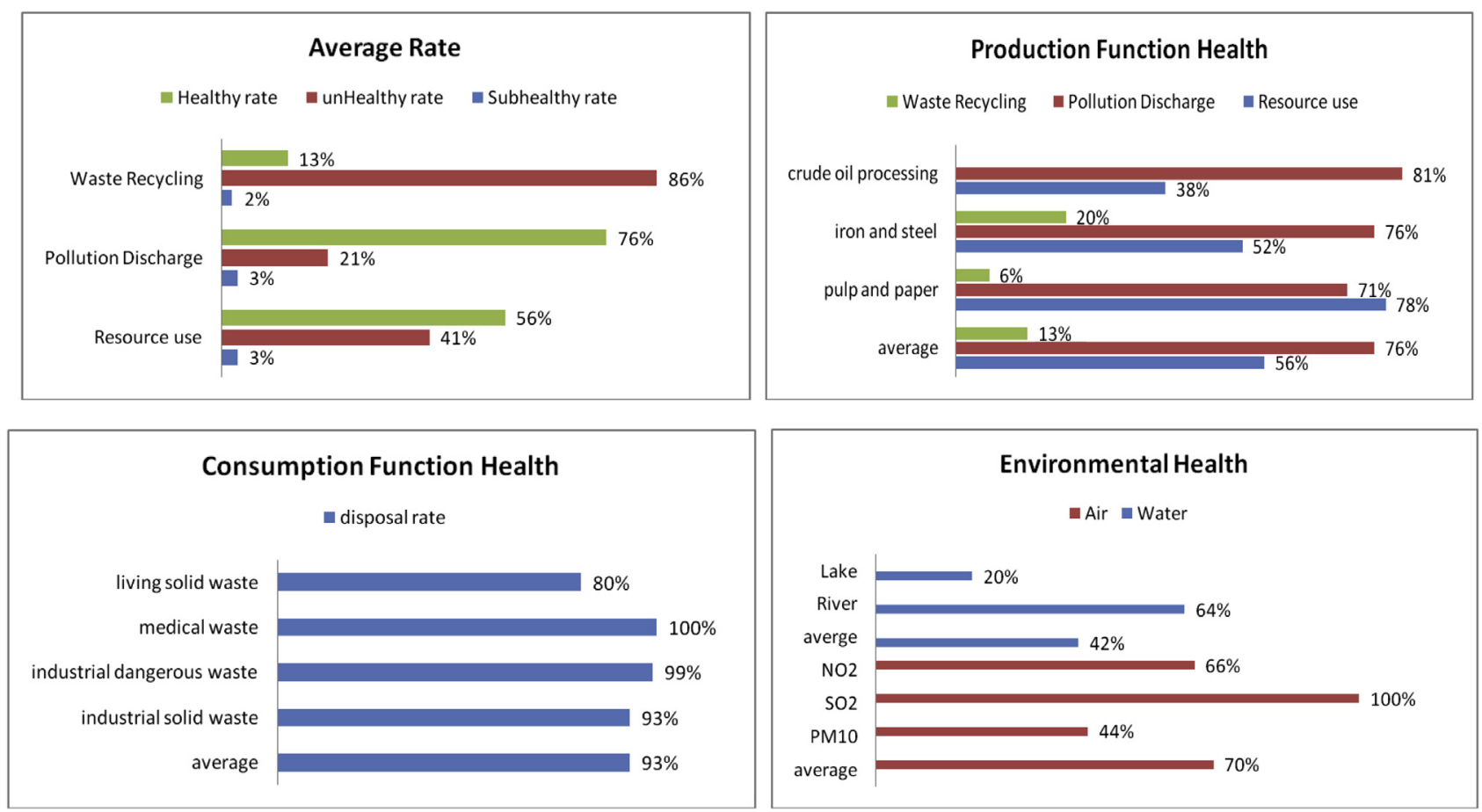

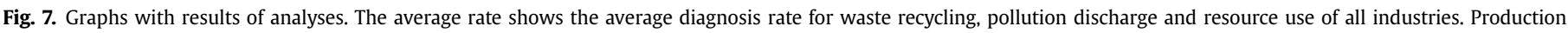

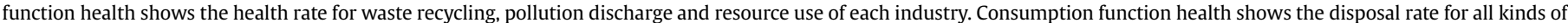
waste. Environmental health shows standard-meeting rate of environmental function zone for air and water environment.

$757 \mathrm{t} /$ year, with maximum permissible discharges of approximately 44,859 and 1235 t/year, respectively. Actual COD and ammonia nitrogen discharges were approximately 178,733 and 16,998 t/year, exceeding the corresponding maximum permissible discharge limits four-fold and fourteen-fold respectively (Table 8). Thus, the situation for waste water discharge was unhealthy, since water quality cannot meet the national standards for $\mathrm{COD}$ and $\mathrm{NH}_{3}-\mathrm{N}$.

Thus, we can diagnose that the water supply was sub-healthy and the water quality was unhealthy in Tianjin in 2002. This highlights the need to control water pollution in Tianjin and to resolve water supply problems. Local water resources should be protected and water resources from other locations should be explored. The efficiency of water use and the water recycle rate should be improved, and water-saving industries should be promoted. Greater priority could be given to the development of industries that save water and citizens could be encouraged to purchase water-saving products and to conserve water in their daily life. To resolve the water quality problems, there should be strict control of total discharge quantities and environmentallyfriendly enterprises should be developed instead of highly polluting industries.

\subsection{Discussion}

The case studies in this paper demonstrate that the health diagnosis approach is valid and feasible. The results let the decision maker know the main health problems, including water and air quality problems, as well as the reasons for the problems, which include resources use efficiency, pollution discharge and recycling. This information allows decision makers to make suitable decisions to maintain urban ecosystem health. Because the case studies are lacking a complete data set that includes function status, criteria, environmental, social and economic effects, the case studies only illustrate the diagnosis approach rather than a robust diagnosis of urban ecosystem health. Furthermore, social and economic effect indicators also should be considered in the future. Development of standard systems and a process-based inventory database for assessing urban ecosystem health is also another challenge. Considering the data complexity and dynamics, we also suggest implementation of the proposed approach within the framework of the cyber-physical-social environment (Zhuge, 2011, 2012). Data can be automatically collected in real-time through sensors and linkages between health problems and their causes can be

Table 8

Input-output analysis for water resources in Tianjin.

\begin{tabular}{|c|c|c|c|c|c|c|c|c|c|}
\hline \multirow[t]{3}{*}{ Items } & \multicolumn{3}{|c|}{ Input (water resources) $\left(10^{8} \mathrm{~m}^{3}\right)$} & \multirow{2}{*}{\multicolumn{2}{|c|}{$\begin{array}{l}\text { Output (waste water) }(\mathrm{t} / \\
\text { year) } \\
\text { Discharge }(G)^{\mathrm{b}}\end{array}$}} & \multirow{2}{*}{\multicolumn{2}{|c|}{ Carrying capacity $(C)^{\mathrm{c}}$}} & \multirow{2}{*}{\multicolumn{2}{|c|}{$\begin{array}{l}\text { Maximum permissible } \\
\text { discharge }(K)^{c}\end{array}$}} \\
\hline & \multirow[t]{2}{*}{ Demand $(F)^{\mathrm{a}}$} & \multirow{2}{*}{$\begin{array}{l}\text { Supply }^{\mathrm{a}} \\
\text { Local }(L)\end{array}$} & \multirow[t]{2}{*}{ Total $(T)$} & & & & & & \\
\hline & & & & COD & $\mathrm{NH}_{3}-\mathrm{N}$ & COD & $\mathrm{NH}_{3}-\mathrm{N}$ & COD & $\mathrm{NH}_{3}-\mathrm{N}$ \\
\hline Value & 19.6 & 13.34 & 19.96 & 178,733 & 16,998 & 30,340 & 757 & 44,859 & 1235 \\
\hline Situation & \multirow{2}{*}{\multicolumn{3}{|c|}{$\begin{array}{l}L \leq F \leq T \\
\text { Sub-healthy }\end{array}$}} & \multirow{2}{*}{\multicolumn{4}{|c|}{$\begin{array}{l}G_{\mathrm{COD}}>K_{\mathrm{COD}}, G_{\mathrm{NH} 3-\mathrm{N}}>K_{\mathrm{NH} 3-\mathrm{N}} \\
\text { Unhealthy }\end{array}$}} & & \\
\hline Assessment & & & & & & & & & \\
\hline
\end{tabular}

${ }^{a}$ L.-X. Li, Study on Water Resources Security in Tianjin, 2005, Master thesis, Tianjin University.

b Environmental Communiqué (2002), Environmental Agency of Tianjin.

c L. Wang, Study on Total Capacity Control for Main Water Pollutants of Tianjin (2005), Doctoral Dissertation, Tianjing University. 
extended to cyberspace, physical space and social space to support intelligent decision making.

\section{Conclusions}

Urban ecosystem health is a crucial issue and one of the most significant challenges in urban ecology. The main purpose of a health diagnosis is to help decision makers to know the pathogeny of an urban ecosystem and prescribe solutions for the treatment of the illness. Healthy urban development should ensure sound material cycling between urban and natural ecosystems. Our material flow-based perspective provides a new framework for evaluating urban ecosystem health. The most valuable contribution of this study lies in establishing a link between problems and causes through a material flow-based approach and in achieving the aim of combining valid diagnosis and feasible management. Therefore, the approach provides a useful means for decision makers to make practical feasible and targeted strategies for maintaining urban ecosystem health, and also contributes to a better relationship between natural and urban ecosystems.

This paper establishes a diagnosis approach that includes function analysis, input-output analysis, health assessment, and function optimization by a material flow perspective. Distinguished from the synthesis approaches, this approach has process analysis characteristics and has a function-effect based indicator system including production function, consumption function and environmental effects. The diagnosis reflects both system internal function and the environmental effects. The case studies show that, through the diagnosis, decision makers can know not only the health problems such as environmental pollution but also know the corresponding root causes such as pollution sources. The results of the diagnosis can provide useful information for decision makers to effectively identify problems during the resource utilization and waste discharge process, and to formulate targeted strategies to resolve these problems for healthy urban development.

Since an urban ecosystem is a complex system that integrates social, economic and eco-environmental subsystems, a robust diagnosis for this complex system needs a complete data support system including production function, consumption function, ecoenvironmental effect, and social-economic effect. Future work will focus on establishing a process-based inventory database for the indicator system and perfecting national standards for each resource and pollutant.

\section{Acknowledgments}

We acknowledge the support of the National Natural Science Foundation of China (Grant Nos. 71033005, 71173208). We express our grateful thanks to Academician Rusong Wang for his helpful suggestions and support. We also appreciate the anonymous reviewers who gave us important comments and suggestions.

\section{References}

Alberti, M., Marzluff, J.M., 2004. Ecological resilience in urban ecosystems: linking urban patterns to human and ecological functions. Urban Ecosyst. 7, 241-265.

Alcamo, J., Bennett, E.M., 2003. Ecosystems and Human Well-being: a Framework for Assessment. Island Press, Washington, DC.

Brunner, P.H., Rechberger, H., 2004. Practical Handbook of Material Flow Analysis. Lewis Publishers, New York.
Caeiro, S., Ramos, T.B., Huisingh, D., 2012. Procedures and criteria to develop and evaluate household sustainable consumption indicators. J. Clean. Prod. 27, $72-91$.

Carpenter, S.R., Westley, F., Turner, M.G., 2005. Surrogates for resilience of socialecological systems. Ecosystems 8, 941-944.

Costanza, R., 1992. Toward an operational definition of ecosystem health. In: Costanza, R., Norton, B.G., Haskell, B.D. (Eds.), Ecosystem Health: New Goals for Environmental Management. Island Press, Washington, DC, pp. 239-256.

CPS (cleaner production standards), iron and steel industry, HJ/T 189-2006, HJ/T 427-2008, HJ/T 428-2008, HJ/T 318-2006, HJ 470-2009; pulp and paper industry, $\mathrm{HJ} / \mathrm{T}$ 339-2007, HJ/T 340-2007, HJ 468-2009; petroleum refinery industry, HJ/T 125-2003, HJ 443-2008.

Dickinson, G., Murphy, K., 1998. Ecosystems. Routledge, London.

Guidotti, T.L., 1995. Perspective on the health of urban ecosystems. Ecosyst. Health 1, 141-149.

Hansen, J.W., 1996. Is agricultural sustainability a useful concept? Agric. Syst. 50, $117-143$.

Harper, E.M., Graedel, T.E., 2004. Industrial ecology: a teenager's progress. Technol. Soc. $26,433-445$.

Hruska, K., 2006. Notes on the evolution and organization of the urban ecosystem. Urban Ecosyst. 9, 291-298.

Landis, J.D., 1995. Imagining land use futures: applying the California urban futures model. J. Am. Plann. Assoc. 61, 438-457.

Liu, G.Y., Yang, Z.F., Chen, B., Ulgiati, S., 2009. Emergy-based urban health evaluation and development pattern analysis. Ecol. Model. 220, 2291-2301.

Montefalcone, M., 2009. Ecosystem health assessment using the Mediterranean seagrass Posidonia oceanica: a review. Ecol. Indic. 9, 595-604.

Rapport, D.J., 1998a. Symptoms of pathology in the Gulf of Bothnia (Baltic Sea): ecosystem response to stress from human activity. Biol. J. Linn. Soc. 37, 33-49.

Rapport, D.J., Bohm, G., Buckingham, D., 1999. Ecosystem health: the concept, the ISEH, and the important tasks ahead. Ecosyst. Health 5, 82-90.

Rapport, D.J., Costanza, R., McMichael, A., 1998b. Assessing ecosystem health. Tree $13,397-402$.

Spiegel, J.M., Bonet, M., Yassi, A., Molina, E., Concepcion, M., Mast, P., 2001. Developing ecosystem health indicators in Centro Habana: a community-based approach. Ecosyst. Health 7, 15-26.

Su, M.R., Yang, Z.F., Chen, B., 2009b. Set pair analysis for urban ecosystem health assessment. Commun. Nonlin. Sci. Numer. Simul. 14 (4), 1773-1780.

Su, M.R., Yang, Z.F., Chen, B., Ulglati, S., 2009a. Urban ecosystem health assessment based on emergy and set pair analysis - a comparative study of typical Chinese cities. Ecol. Model. 220 (18), 2341-2348.

Takano, T., Nakamura, K., 2001. An analysis of health levels and various indicators of urban environments for healthy cities projects. J. Epidemiol. Commun. Health $55,263-270$.

Van der Werf, H.M.G., Kanyarushoki, C., Corson, M.S., 2009. An operational method for the evaluation of resource use and environmental impacts of dairy farms by life cycle assessment. J. Environ. Manage. 90, 3643-3652.

Van der Werf, H.M.G., Petit, J., 2002. Evaluation of the environmental impact of agriculture at the farmlevel: a comparison and analysis of 12 indicator-based methods. Agric. Ecosyst. Environ. 93, 131-145.

Waltner-Toews, D., Neudoerffer, C., Joshi, D.D., Tamang, M.S., 2005. Agro-urban ecosystem health assessment in Kathmandu, Nepal: epidemiology, systems, narratives. EcoHealth 2, 155-164.

WCED (World Commission on Environment and Development), 1987. Our Common Future. Oxford University Press, New York.

Wen, X.M., Xiong, Y., 2008. Assessment on urban ecosystem health based on attribute theory. Syst. Eng. 26 (11), 42-46 (in Chinese).

Wiegand, J., Raffaelli, D., Smart, J.C.R., White, P.C.L., 2010. Assessment of temporal trends in ecosystem health using a holistic indicator. J. Environ. Manage. 91 (7) $1446-1455$.

Xu, F.L., Zhao, Z.Y., Zhan, W., Zhao, S.S., Dawson, R.W., Tao, S., 2005. An ecosystem health index methodology (EHIM) for lake ecosystem health assessment. Ecol. Modell. 188, 327-339.

Zeng, Y., Shen, G.X., Guang, S.F., Wang, M., 2005. Assessment of urban ecosystem health in Shanghai. Resour. Environ. Yangtze Basin 14 (2), 208-212 (in Chinese).

Zhang, H., Wang, X.R., Ho, H.H., Yong, Y., 2008. Eco-health evaluation for the Shanghai metropolitan area during the recent industrial transformation (19902003). J. Environ. Manage. 88, 1047-1055.

Zhou, W.H., Wang, R.S., 2005. An entropy weight approach on the fuzzy synthetic assessment of Beijing urban ecosystem health, China. Acta Ecol. Sin. 25 (12), 1344-1351 (in Chinese).

Zhuge, H., 2012. The Knowledge Grid - Toward Cyber-Physical Society. World Scientific Co.

Zhuge, H., 2011. Semantic linking through spaces for cyber-physical-socio intelligence: a methodology. Artif. Intell. 175, 988-1019. 